\title{
2013 Statement on Human Papillomavirus DNA Test Utilization
}

\author{
Diane Davis Davey ${ }^{a}$ Robert Goulart ${ }^{b}$ Ritu Nayar ${ }^{c}$ \\ on behalf of the Cytopathology Education and Technology Consortium (CETC) \\ ${ }^{a}$ Department of Clinical Sciences, University of Central Florida College of Medicine and Orlando Veterans Affairs \\ Medical Center, Orlando, Fla., b New England Pathology Associates, PC and LifePath Partners, LLC, Mercy Medical \\ Center, Springfield, Mass., and ' Department of Pathology, Northwestern University, Feinberg School of Medicine, \\ Chicago, III., USA
}

\begin{abstract}
This statement from the Cytopathology Education and Technology Consortium summarizes appropriate and inappropriate uses of human papillomavirus testing in cervical cancer screening based on guidelines from the American Society for Colposcopy and Cervical Pathology and the American Cancer Society.

(c) 2014 S. Karger AG, Basel
\end{abstract}

In 2009, the Cytopathology Education and Technology Consortium issued a statement on human papillomavirus (HPV) DNA test utilization that was published in multiple journals [1]. This statement was a concise summary of the clinical indications for high-risk or oncogenic HPV testing based on guidelines from the American Society for Colposcopy and Cervical Pathology (ASCCP) and the American Cancer Society (ACS) published from 2002 through 2007 [2, 3]. These organizations have since published newer consensus guidelines addressing HPV testing $[4,5]$, and the previous summary no longer reflects current screening and management guidelines.

High-risk HPV testing has proven utility in both cervical cancer screening and management. The 2012 screening guidelines endorsed by the ACS, ASCCP, and the
American Society for Clinical Pathology state that combined cervical cytology and HPV testing is now the preferred strategy for women aged $\geq 30$ years. The 2012 ASCCP guidelines for the management of abnormal cervical cancer screening tests and cancer precursors utilize cotesting extensively as both a sensitive and efficient way to manage and follow these women. Inappropriate or toofrequent screening, including HPV testing, can lead to increased costs without proven benefit, and may also cause patient harm by overtreatment. The educational statement below is intended to improve adherence to current guidelines, thereby improving the health care of women. The American College of Obstetricians and Gynecologists affirms these recommendations and the US Preventive Services Task Force states that cotesting is acceptable $[6,7]$.

CETC member organizations include: American Society of Cytopathology, American Society for Clinical Pathology, American Society for Cytotechnology, College of American Pathologists, International Academy of Cytology, and Papanicolaou Society of Cytopathology. Original publication: Davey DD, Goulart R, Nayar R; Cytopathology Education and Technology Consortium (2013): 2013 statement on human papillomavirus DNA test utilization. Cancer Cytopathol 2013, DOI: $10.1002 /$ cncy.21388. This material is reproduced with permission from the American Cancer Society and John Wiley \& Sons, Inc.

\section{KARGER}

E-Mail karger@karger.com

www.karger.com/acy
(C) 2014 S. Karger AG, Basel

$0001-5547 / 14 / 0582-0113 \$ 39.50 / 0$
Correspondence to: Prof. Ritu Nayar

Department of Pathology, Northwestern University

Feinberg School of Medicine

Chicago, IL 60611 (USA)

E-Mail r-nayar@northwestern.edu 


\begin{tabular}{|lccccccc|}
\hline \multirow{2}{*}{ Age } & \multirow{2}{*}{$\begin{array}{l}\text { Routine } \\
\text { screening }\end{array}$} & \multicolumn{5}{c|}{ Triage } \\
\cline { 3 - 8 } & & UNSAT & ASC-US & LSIL & ASC-H & AGC & HSIL \\
\hline $21-24$ & 2.1 & 2.5 & 1.2 & 2.4 & 2.3 & 2.3 & 2.3 \\
$25-29$ & 2.1 & 2.5 & 1.2 & 2.4 & 2.5 & 2.5 & 2.5 \\
$30+$ & $1.1^{\mathrm{b}}$ & 2.5 & 1.2 & $1.4^{c}$ & 2.5 & 2.5 & 2.5 \\
\hline
\end{tabular}

Preceding results for which cotesting surveillance (without colposcopy) is appropriate

\begin{tabular}{lcccccc}
\hline Age & NILM HPV & ASC-US HPV- & LSIL HPV- & ASC-H & AGC $^{\text {a }}$ & HSIL \\
\hline $21-24$ & 2.1 & 1.3 & 2.4 & & \\
$25-29$ & 2.1 & 1.3 & 2.4 & & \\
$30+$ & $1.1 .2^{\mathrm{d}}$ & 1.3 & 1.4 & & \\
\hline
\end{tabular}

b

Preceding results for which cotesting surveillance is appropriate post-colposcopic findings of $\leq$ CIN I

\begin{tabular}{lcccccc}
\hline Age & NILM HPV + & ASC-US & LSIL & ASC-H & AGC & HSIL \\
\hline $21-24$ & 2.1 & 1.5 & 1.5 & 1.6 & 1.7 & 1.6 \\
$25-29$ & 2.1 & 1.5 & 1.5 & 1.6 & 1.7 & 1.6 \\
$30+$ & $1.1 .2^{\mathrm{d}}$ & 1.5 & 1.5 & 1.6 & 1.7 & 1.6
\end{tabular}

c

Age

Cotesting surveillance post-treatment (biopsy $\geq$ CIN 2)

$21-24$

$25-29$

1.9

$30+$

Cotest at 12 and 24 months (and then 3 years later)

Cell color indicates if HPV testing (or cotesting) is preferred (green), acceptable but not preferred (yellow) or not appropriate (red). Numbers in table cells refer to the text outline.

${ }^{a}$ For AGC results, HPV testing is not recommended as a triage tool; however, a negative HPV test may be helpful in suggesting endometrial versus endocervical origin. Cotesting is recommended at 12 and 24 months post-colposcopy.

${ }^{b}$ For women 30 and older who are both cytology and HPV negative, repeat both tests only after a 5-year interval.

${ }^{c}$ For women 30 and older, HPV testing is preferred as a cotest, with repeat cotesting at 1 year if HPV is negative. HPV testing may be ordered as a triage for LSIL in post-menopausal patients.

${ }^{d}$ NILM/HPV+: Repeat both tests in 1 year (or perform HPV genotyping). Colposcopy is recommended if HPV positive on repeat regardless of cytology result.

Fig. 1. Appropriate uses of human papillomavirus (HPV) testing and cotesting [Papanicolaou (Pap) test with HPV] are shown in routine screening and triage (a), as surveillance after abnormal $\mathrm{Pap} / \mathrm{HPV}$-positive (+) findings without colposcopy (b), after colposcopy (c), and after treatment (d). UNSAT indicates an unsatisfactory Pap test. ASC-US = Atypical squamous cells of undeter- mined significance; LSIL = low-grade squamous intraepithelial lesion; ASC-H = atypical squamous cells, cannot exclude high-grade squamous intraepithelial lesion; AGC = atypical glandular cells; $\mathrm{HSIL}=$ high-grade squamous intraepithelial lesion; NILM = negative for intraepithelial lesion or malignancy; - = negative; $\mathrm{CIN}=$ cervical intraepithelial neoplasia. 


\section{High-risk (oncogenic) HPV DNA testing is appro-} priate in the following circumstances:

1.1. Routine cervical cancer screening in conjunction with cervical cytology (cotesting) for women aged 30 to 65 years (for women aged 30 to 65 years with cytology reported as absent or insufficient endocervical/transformation zone component, early repeat cytology is not indicated and cotesting is preferred).

1.1.1. For women whose cytology and HPV results are both negative, repeat both tests only after a 5 -year interval (applies only to routine screening; for women with negative cotests after previous abnormal cytology, see below).

1.1.2. For women whose cytology results are negative and whose HPV test is positive, repeat both tests within 1 year or perform HPV type 16/18 (HPV16/18) genotyping; women with HPV16/18-positive results are referred for colposcopy.

1.2. Initial triage management of women aged $\geq 25$ years with a cytology result of atypical squamous cells of undetermined significance (ASC-US). Triage management is acceptable for women aged 21 years to 24 years, but repeat cytology at 12 months is preferred.

1.3. Follow-up cotesting of women aged $\geq 25$ years with preceding HPV-negative ASC-US at 3 years as per ASCCP management guidelines $[5,8]$ or at 5 years according to the 2012 ACS/ASCCP/American Society for Clinical Pathology screening guidelines [4].

1.4. Initial triage management of women aged $\geq 30$ years with low-grade squamous intraepithelial lesion (LSIL), generally when performed as part of a screening cotest. In postmenopausal patients, HPV testing may be ordered as a triage for LSIL. If the HPV result is negative in either age group, repeat cotesting at 12 months is recommended.

1.5. Postcolposcopy cotesting at 12 months for women aged $\geq 25$ years with either no lesion or cervical intraepithelial neoplasia (CIN) 1 and with a preceding 'lesser' cytology result (ASC-US, LSIL, negative cytology with HPV16 or HPV18 positivity, or persistent HPV infection).

1.6. Postcolposcopy cotesting of women aged $\geq 25$ years at 12 months and 24 months in those with no lesion or CIN1 when the preceding cytology result was a highgrade squamous intraepithelial lesion (HSIL) or atypical squamous cells, cannot exclude HSIL (ASC-H).

1.7. Postcolposcopy cotesting of women aged $\geq 21$ years at 12 months and 24 months in those with no lesion or CIN1 on colposcopy and a preceding cytology result of atypical glandular cells, not otherwise specified (AGC NOS).
1.8. Follow-up cotesting of women aged $\geq 30$ years at 3 years after previous negative cotest results with various preceding cytology abnormalities and no evidence of a high-grade lesion on colposcopy. An example is a woman with LSIL, CIN1 on biopsy, and a negative cotest at 12 months; see 2012 ASCCP algorithms for more details [5].

1.9. Posttreatment cotesting surveillance of women aged $\geq 25$ years at 12 months and 24 months (and then 3 years later) with treated CIN2 and CIN3. See 2012 ASCCP algorithms for details on women aged 21 years to 24 years [5].

2. High-risk (oncogenic) HPV testing is generally not appropriate in the following situations:

2.1. Routine cervical cancer screening in women aged $<30$ years.

2.2. Routine cervical cancer screening with cotesting more often than every 5 years when previous cotest results were negative (and no prior abnormality).

2.3. Initial triage or management of women aged $<25$ years with any cytologic abnormality (HPV triage is acceptable for ASC-US, but repeat cytology is preferred).

2.4. Initial triage or management of women aged $<30$ years with LSIL.

2.5. Initial triage or management of women of any age with unsatisfactory cytology, ASC-H, HSIL, or atypical glandular cells of any type.

3. Repeat high-risk HPV testing should generally not be performed before 12 months.

4. There is currently no evidence-based guideline recommending HPV genotyping as a management tool in women with abnormal cytology results such as ASC-US.

5. Testing for low-risk (nononcogenic) HPV types has no role in cervical cancer screening or in the triage, management, or follow-up of women with abnormal cytology results.

The intent of this summary is to facilitate provider education and to encourage the appropriate utilization of HPV testing. Clinical judgment should always be used when applying a guideline to an individual patient because it is impossible to develop guidelines that will apply to all situations.

\section{Acknowledgement}

In addition to the listed authors, the following individuals contributed to the review of this statement: Dr. Teresa Darragh, Dr. Debbie Saslow, Dr. Mark Schiffman, Dr. Diane Solomon, and Dr. Mark Stoler. 


\section{Funding Support}

No specific funding was disclosed.

\section{Conflict of Interest Disclosures}

The authors made no disclosures.

\section{References}

-1 Solomon D, Papillo JL, Davey DD; Cytopathology Education and Technology Consortium: Statement on human papillomavirus DNA test utilization. Arch Pathol Lab Med 2009; 133:1276-1277; Am J Clin Pathol 2009; 131:768-769; Acta Cytol 2009;53:247-248; Cancer (Cancer Cytopathol) 2009;117:154156; Diagn Cytopathol 2009;37:542-543; J Low Genit Tract Dis 2009;13:135-136.

-2 Saslow D, Runowicz CD, Solomon D, et al; American Cancer Society: American Cancer Society guideline for the early detection of cervical neoplasia and cancer. CA Cancer J Clin 2002;52:342-362.

-3 Wright TC Jr, Massad LS, Dunton CJ, Spitzer M, Wilkinson EJ, Solomon D; 2006 American Society for Colposcopy and Cervical Patholo-
gy-Sponsored Consensus Conference: 2006 consensus guidelines for the management of women with abnormal cervical cancer screening tests. Am J Obstet Gynecol 2007;197:346355.

-4 Saslow D, Solomon D, Lawson HW, et al; ACS-ASCCP-ASCP Cervical Cancer Guideline Committee: American Cancer Society, American Society for Colposcopy and Cervical Pathology, and American Society for Clinical Pathology screening guidelines for the prevention and early detection of cervical cancer. Am J Clin Pathol 2012; 137:516-542; CA Cancer J Clin 2012;62: 147-172.

5 Massad LS, Einstein MH, Huh WK, et al; 2012 ASCCP Consensus Guidelines Conference:
2012 updated consensus guidelines for the management of abnormal cervical cancer screening tests and cancer precursors. Obstet Gynecol 2013;121:829-846.

6 Committee on Practice Bulletins-Gynecology: ACOG Practice Bulletin Number 131: screening for cervical cancer. Obstet Gynecol 2012;120:1222-1238.

7 US Preventive Services Task Force. Screening for Cervical Cancer. uspreventiveservicestaskforce.org/uspstf/uspscerv.htm (accessed September 18, 2013).

8 Katki HA, Schiffman M, Castle PE, et al: Fiveyear risks of CIN $3+$ and cervical cancer among women with HPV testing of ASC-US Pap results. J Low Genit Tract Dis 2013;17(5 suppl 1):S36-S42. 


\section{Erratum}

In the article by Davis Davey D, Goulart R, Nayar R, on behalf of the Cytopathology Education and Technology Consortium (CETC), entitled '2013 statement on human papillomavirus DNA test utilization' [Acta Cytologica 2014;58:113-116, DOI: 10.1159/000358795], the authors wish to correct the title and text to remove the word 'DNA', as the statement also allows for use of any clinically validated HPV testing method. One RNA testing method is now approved by the Food and Drug Administration in addition to several DNA testing methods. Most of the studies that supported the previous HPV test guidelines involved DNA testing, but it is recognized that other molecular testing methods have demonstrated similar performance. The title and the first sentence should include the words 'human papillomavirus test' instead of 'human papillomavirus DNA test', and statement 1 should be 'HPV testing' instead of 'HPV DNA testing'. The corrected reference should read: Davis Davey D, Goulart R, Nayar R, on behalf of the Cytopathology Education and Technology Consortium (CETC): '2013 statement on human papillomavirus test utilization' [Acta Cytologica 2014;58:113-116, DOI: 10.1159/000358795]. The authors regret this error. 